\title{
Integrating research, teaching and practice in the context of new institutional policies: a social practice approach
}

\author{
Susan Mathieson ${ }^{1}$ \\ Published online: 8 March 2019 \\ (C) The Author(s) 2019
}

\begin{abstract}
Most research on the implementation of research-informed teaching has focused on influencing the individual practices of academics. However, social practice theory has criticised individualist approaches, arguing that attention must be paid to the context of practice, which in the academic context requires a focus on how academics articulate agency in their teaching practices in relation to specific contextual opportunities and constraints. This small-scale qualitative study in a UK university explores how academics across eight disciplines reshaped their understandings and practices of research-informed teaching in the context of a change in institutional mission from teaching and professional practice to incorporate expectations around research, drawing on developments in social practice theory when applied to academic workgroups. Understandings of identity and agency developed in postcolonial literary theory are used to further explore the academic work involved in creating new narratives for researchinformed teaching in the context of changing, and often contradictory discourses of research, teaching and practice. This has implications for approaches to implementing researchinformed teaching, which should recognise the work of academics in developing new narratives for research-informed teaching in the context of unique configurations of the nexus between research, teaching and practice in different disciplines. Social practice theory provides a lens for considering the contextual elements impacting on academic approaches to researchinformed teaching, while approaches to narrative borrowed from postcolonial literary theory foreground the agency of academics in working across contradictions that surfaced with changes to the nexus between research, teaching and practice, to create emergent practices of research-informed teaching.
\end{abstract}

Keywords Academic identity $\cdot$ Academic practices $\cdot$ Narrative $\cdot$ Research-teaching nexus . Research-informed teaching $\cdot$ Disciplines

Susan Mathieson

susan.mathieson@northumbria.ac.uk

1 Teaching Excellence and Student Outcomes, Northumbria University, Newcastle upon Tyne, UK 


\section{Introduction}

Research has identified the need for further investigation into what constrains and enables the implementation of research-informed teaching (Brew and Mantai 2017). However, most research has focused on influencing individual practices by identifying differences between academics' beliefs about learning and teaching (Brew and Mantai 2017; Wilson et al. 2012) or on institutional drivers for research-informed teaching (Jenkins and Healey 2005).

This research focuses on how academics construct narratives of research-informed teaching in disciplinary workgroups, drawing on developments in social practice theory when applied to academic workgroups (Trowler 2008; Mathieson 2012). Social practice theory emphasises learning through engaging in social practices (Blackler 1995), but pays less attention to individual identity and agency. However, academics often have considerable scope to step back from the immediate context of practice in recreating their teaching practices. This research draws on postcolonial literary theory to foreground academic agency in reconstructing social practices, drawing attention to the creative work of academics in constructing and reconstructing disciplinary identities and practices of research-informed teaching in the context of institutional changes in the relationship between research, teaching and professional practice.

The study is based in a UK post-1992 university that developed its reputation around strong links to industry and the professions, while aspiring to excellent teaching. However, with a change in institutional leadership, the mission shifted from teaching and professional practice to incorporate expectations around research as measured in the UK's Research Excellence Framework (REF). Initially, there was an assumption by senior management that research-led teaching would flow naturally from putting research-active lecturers in front of students. However, performative measures including the National Student Survey (NSS) highlighted student dissatisfaction with teaching that was not actively engaging them in their learning. This led to the development of a research-informed teaching policy to give direction to teaching aligned to the changed institutional mission. This policy defined research-informed teaching in relation to Jenkins and Healey's quadrant (2005), which privileges active student engagement through enquiry-based learning over more passive lecture-led exposure to academic research, as well as Boyer's Scholarship of Engagement (1998) proposing an integrated approach to research, teaching and engagement through critical enquiry. However, once the policy was adopted, there was little recognition by senior management of the academic work needed to make the policy meaningful across diverse disciplinary contexts. This research draws attention to the academic work of re-narrating research-informed teaching in the context of changes in the relationship between research, teaching and practice.

This small-scale qualitative study draws on in-depth semi-structured interviews with eight academics across different discipline groups. Interviews were analysed to identify how academics reinvented their teaching in response to the transition from teaching and professional practice to incorporate the new emphasis on research. A social practice analytical framework was developed identifying the contextual contingencies academics considered in reconfiguring research-informed teaching. This was supplemented by understandings of agency developed in postcolonial literary theory, focusing on the work of academics in recreating coherent narratives for research-informed teaching across contradictory discourses of research, teaching and professional practice.

The research highlights differences in contextual considerations across disciplinary workgroups, which had less to do with epistemological differences between disciplines, but 
more with the way research, teaching and professional practice were being reconfigured in disciplinary workgroups in response to a changing institutional mission.

\section{Literature review}

This section starts with an overview of research on approaches to integrating research and teaching, arguing for a social practice approach that foregrounds the role of disciplinary workgroups in shaping approaches to integrating research into teaching. It then explores the contribution of social practice theory to understandings of academic identity and agency in contemporary higher education and the role of disciplinary workgroups in this. It argues that narrative approaches to analysing interviews with academics, drawn from postcolonial literary theory, can shed further light on the processes through which academics create and recreate their identities and practices in changing contexts.

\section{Integrating research into teaching}

It has been argued that the integration of research into teaching is critical in bringing about the learning expected in higher education (Hattie and Marsh 1996; Boyer Commission 1998). There is extensive research demonstrating the diversity of ways that research is embedded into the curriculum and linking these to different outcomes for student learning. Enquiry-based learning that involves students actively in doing research has been argued to have more beneficial outcomes for student learning than passive, teacher-led, content-focused teaching (Brew 2003; Jenkins and Healey 2005), while involving undergraduate students as partners in academic research has been advocated (Healey et al. 2015; Brew and Mantai 2017).

It is also argued that the integration of research and teaching is not automatic, but needs to be consciously developed to embed it into student learning, particularly at the undergraduate level (Brew 2003). However, Brew and Mantai (2017) identified that there is still a lack of indepth investigations into what constrains and enables the integration of research into the undergraduate curriculum. A range of strategies for integrating research into teaching, focusing on individual academics, have been advocated. Studies have demonstrated how academics' definitions of undergraduate research (Brew and Mantai 2017) and beliefs about learning and teaching (Wilson et al. 2012) influence the way research is taught. Research has also identified institutional constraints to research-informed teaching (Jenkins and Healey 2005), including the weakness of institutional strategies promoting the integration of research with teaching, time and funding constraints and lack of recognition and rewards.

There is some research into the role of disciplines and departments in shaping academics' approaches to implementing research-informed teaching; however, this research focuses mainly on the significance of different disciplinary epistemologies (Durning and Jenkins 2005). Since these studies, developments in social practice theory have shed light on the role of disciplinary workgroups in mediating academic practices (Trowler 2008; Mathieson 2012; Englund et al. 2018). However, the significance of this research for the implementation of research-informed teaching has not been explored.

Social practice theories of academic workgroups criticise both the methodological individualism underpinning approaches focusing on individual academics and the technical rationalism underpinning structuralist interventions. Instead, they argue that attention needs to be paid to the context of practice (Fanghanel and Trowler 2008). In relation to understanding teaching 
enhancement, social practice perspectives focus on how academics develop their teaching practices in the context of specific sets of relations and contextual opportunities and constraints, with a focus on differences in practices across disciplinary workgroups (Trowler 2008; Mathieson 2012).

\section{Developing a social practice account of disciplinary workgroups}

The discipline has been acknowledged as a significant source of identity for academics, despite the erosion of disciplines in the face of increased managerialism and performativity in higher education (Becher and Trowler 2001; Henkel 2000). As Henkel argues, it is the context within which 'academics construct their identities, their values, the knowledge base of their work, their modes of working and their self-esteem' (Henkel 2000:22).

However, the significance of disciplinary epistemologies in determining differences in academic cultures has been questioned from a social practice perspective (Mathieson 2012; Trowler 2014), in particular accounts that focus on the way different approaches to teaching are shaped by the epistemological characteristics of disciplines (Neumann 2001). Epistemological accounts have been critiqued for offering an over-structuralist account of disciplines that fail to take account of the scope for agency in response to localised contextual considerations. Furthermore, it is argued that the power of the 'academic tribes and territories' of the disciplines has been weakened by both State and market (Becher and Trowler 2001) and that the nature of knowledge itself is changing from the power of knowledge to describe the world, to a more performative approach focusing on the use value of knowledge, which further dilutes the power of disciplinary epistemologies (Lyotard 1984; Gibbons et al. 1994; Barnett 2000).

Applications of social practice theory in higher education have viewed disciplinary workgroups as shaped less by epistemological differences between disciplines, focusing instead on the way academics' approaches to teaching are shaped by a range of contextual factors impacting on disciplinary workgroups in different institutional settings (Trowler 2008; Mathieson 2012). While there is debate about the boundaries of academic workgroups (Roxa and Martensson 2009), for the purposes of this research, they are understood as groups of academics involved in developing programmes in a particular discipline, although it is recognised that boundaries may be fluid and overlapping, and cut across research specialisms.

Social practice theory covers a range of theoretical perspectives. The most influential in higher education have been the Communities of Practice tradition (Lave 1993; Wenger 1998) focusing on socially situated learning through engaging in everyday tasks in 'communities of practice' and cultural historical activity theory (CHAT) focusing on 'expansive learning' through engaging with contradictions in 'activity systems' (Blackler 1995, Engestrom 2001). Blackler argues that both traditions "are explicit in their attempts to develop a unified account of knowing and doing, and all emphasise the collective, situated and tentative nature of knowing." (Blackler 1995:1035).

This shift from seeing knowledge as independent of context to an understanding of knowing as situated, mediated, emergent and contested (Blackler 1995) has enabled richer accounts of organisational change as processes of learning. However, social practice theory has been criticised for its weak account of individual agency, for presenting "amalgams of 'practices' which oscillate wildly between voluntarism and determinism, without our being able to specify the conditions under which agents have greater degrees of freedom or, conversely, work under a considerable stringency of constraints" (Archer 2000:6). While accounts of social practice have become increasingly sophisticated, their focus is still primarily 
on practices, rather than individual agency (Reich and Hager 2014). This has also been the tendency when social practice theory has been applied to academic teaching practices (Boud and Brew 2013; Englund et al. 2018). Archer (2000) focuses on how agency is articulated through the 'inner conversation' as a creative and agentic space through which individuals shape their relationship to the structural contexts in which they find themselves. This is particularly significant in universities where academics have considerable agency to step back from their immediate context to reflect individually on contradictions, when developing innovative new practices.

Postcolonial literary theory takes up the theme in CHAT of cultural historical contradictions as the driving force for change, but it focuses on the emergence of new voices as individuals assert their agency in the face of contradictory discourses. This focus on identity and agency makes it valuable in analysing academic narratives of their changing practices of researchinformed teaching.

\section{Postcolonial literary theory and academic agency}

There is a rich body of research on academic identities in the context of higher education change. However, this research has focused less on how academic identities are shaped in disciplinary departments, than by institutional (McNaughton and Billett 2016), and broader societal levels (Henkel 2016; Clegg 2008; Yjiloki and Ursin 2013). Research on academic identities has drawn on narrative theory to understand how academics articulate academic identity and agency in the face of institutional and societal change (Yjiloki and Ursin 2013).

This research draws on approaches to narrative developed in postcolonial literary theory, which sees narratives as a creative space for articulating agency in the face of powerful and often contradictory discourses. Postcolonial literary theory focuses on struggles to articulate a coherent voice across competing discourses. This provides a way of considering the agency of academics in changing their practices of research-informed teaching as a process of negotiation across contradictory discourses of research, teaching and practice. It thus foregrounds the creative work of agency that can become invisible in social practice accounts of practice.

Postcolonial literary theory focuses on the way competing discourses threaten the development of a coherent voice and the creative work involved in developing coherent narratives of the self in the face of contradictory discourses:

Its split narratives are tragic and painful in the extreme, but it is their agony that makes them exemplary texts for our moment. They represent an idea of action and agency more complex than either the nihilism of despair or the utopia of progress. They speak of the reality of survival and negotiation that constitutes the lived moment of resistance, its sorrow and its salvation - the moment that is rarely spoken in the stories of heroism that are enshrined in the histories we choose to remember and recount. (Bhabha 1992:46-57)

Much of the research on research-informed teaching is in the heroic tradition Bhabha refers to, praising individual academics who successfully integrate research into their teaching, offering these up as examples that other academics should be able to emulate if only they had the right knowledge. However, the current research is more interested in academic narratives of negotiation and survival as academics work to reconstruct coherent narratives about how they embed research into teaching in the face of changing, often competing demands of research, teaching and practice. These academic narratives are understood as a creative space where new voices can emerge across contradictory discourses. Postcolonial literary theory also 
foregrounds the provisional and unstable nature of academic narratives of research-informed teaching in the face of changing institutional missions.

\section{Research approach}

This small-scale qualitative study in a UK university draws on interviews with eight academics involved in leading research-informed teaching at undergraduate and postgraduate level across eight discipline groups: law, business, nursing, architecture, digital animation, media, innovation design and history. The disciplines were chosen from all four faculties and across different departments of the University in order to capture the diversity of disciplinary contexts in which academics were renegotiating their teaching practices. The academics interviewed were all involved in some way in programme redesign to incorporate the institutional researchinformed teaching policy. All interviewees were experienced academics, including two professors, three principal lecturers and three senior lecturers, five of whom were men and three women. Because of their involvement in implementing research-informed teaching and their relative seniority, they were able to articulate the complexities of research-informed teaching as practice, as well as their agency in creating new narratives for research-informed teaching across contradictory discourses. In order to protect the anonymity of interviewees, gender, status and in some cases discipline have not been identified in direct quotes.

Semi-structured interviews of $1-1.5 \mathrm{~h}$ explored how academics negotiated the transition from teaching and practice to incorporate the new emphasis on research, both as individuals and within their disciplinary workgroups, exploring the strategies adopted, challenges faced and what this meant for embedding research-informed teaching into the curriculum.

Transcribed interviews were analysed to identify aspects of social practices that academics identified as significant in reshaping research-informed teaching. This included the 'shared repertoire' of tools, rules and concepts; ways of relating between academics, with external 'communities' and with students; changing understandings of the 'joint enterprise' of researchinformed teaching; changing power relations; and changes in identity. Particular attention was paid to contradictions and synergies that surfaced between the discourses of research, teaching and professional practice in the process of recreating coherent narratives for research-informed teaching, with a focus on differences in the ways contradictions surfaced and were resolved by academics across disciplinary workgroups.

\section{Re-narrating research-informed teaching across disciplines}

\section{Integrating or splitting research, teaching and practice}

A key difference that emerged from the interview analysis was whether research, teaching and practice were integrated or split. This powerfully shaped the agency of academics in renarrating research-informed teaching. Where it was considered to be integrated, academics were able to create more coherent narratives that bound their changing practices as researchers with their changing practices as teachers. These differences are explored in the sections below.

This diversity of approaches to linking research, teaching and practice across disciplines resulted from the institutional approach to managing the mission shift towards research, which was through setting performative targets for research, teaching and income generation, which 
allowed faculties and disciplines some scope in how they achieved these targets. In some disciplines, research productivity was developed independently of existing strengths in teaching and professional practice by appointing research-active academics who were not expected to contribute to teaching. However, other faculties and disciplines opted to build research around existing strengths in teaching and professional practice. The decision to integrate or split research, teaching and practice depended on local histories of the development of disciplines, which gave rise to different judgements about the best options for disciplines to make the shift from teaching and professional practice to incorporate research. The academics interviewed were keenly aware of how these decisions shaped their agency in developing research-informed teaching.

\section{Integrating research with teaching}

The law disciplinary workgroup opted to integrate research with teaching, by building research excellence around existing strengths in enquiry-based learning. While new appointments were required to be research-active, they were also expected to be excellent in teaching. At the same time, existing staff who were excellent in teaching and professional practice were supported to develop their research. This support was formalised by giving the coveted research banding to teaching-focused academics, which increased their workload allowance for research into legal education, bringing new rigour to teaching innovation and curriculum change. A feature of the new discipline culture was the regular, well-attended seminars around teaching in the discipline, including joint seminars with other universities, and the discipline was hosting the national conference on legal education, which further focused attention on innovations in the curriculum.

This decision to integrate research and teaching facilitated the development of new academic identities in law for previously teaching-focused academics:

5 years ago if I did any research I wouldn't have considered it part of my everyday job - I would have read articles about curriculum developments at home and considered I'd be doing that out of interest. In my subject area I'd be interested in cases, but that would be to make sure I had an understanding so I could deliver it to students. But now I'm putting in easily equal amounts of time preparing papers - we've got a seminar coming up and I'm putting a paper together, and there's always now the next conference or next seminar to prepare for, and I think for me that has been facilitated by my role - it ties in so closely to my role and I've been given time to develop that, but I think all the staff keenly feel that the research is as important as the teaching, they may not all like that.

This academic was given responsibility for restructuring the undergraduate curriculum around the reconfigured discipline, which was expected to lead to publishable research. It was restructured around three strands representing the three academic groupings that now made up the disciplinary workgroup. A new group of research-active academics with limited practice experience who developed research-led teaching around their specialist areas, a professional practice strand and an enquiry-based learning strand. These strands were developed progressively from the first year and were made explicit to students, where previously there had been a more ad hoc approach to teaching innovation.

Enquiry-based learning had always featured in the fourth year through a student law office, but the new curriculum structure embedded this progressively from the first year. Enquirybased teaching was becoming a hallmark of the discipline workgroup and was increasingly 
recognised through research. It was argued that enquiry-based teaching promoted a unique partnership between academics and students:

The relationships you build with a group of 6 students you have in the student law office is stronger than any of the other student contact you have. And it will be stronger for them. I'm always getting students in contact with me for references. And it's a profound shock for them. We are often working on cases together with them, and I'm saying, 'well I don't know what the answer is, we're just going to have to find it out between us ... how do you think the law applies in this case?' - and I don't know ... And it's truly wonderful when you go into the SLO and find students talking like lawyers talk, saying 'you know it could be like this, but look here, it could be like this', and you can hear these very detailed thoughtful analytical conversations going on - not all the time - and that's wonderful to hear and is hitting a different level. And I think in the SLO there is a very much - not equal because we're assessing them - but a more collaborative approach.

This narrative of enquiry-based learning provided a link between preparation for professional practice and the development of research skills. It was developed by academics who had previously seen themselves as teachers, but had been supported to become research-active. This narrative of research-informed teaching as enquiry-based learning mirrored her own academic journey to integrate research with teaching and professional practice. Research advocates this method of enquiry-based teaching (Healey et al. 2015; Brew and Mantai 2017), and authentic learning through live projects (Wald and Harland 2017) as most likely to support student learning.

The group who was identified as least comfortable with the changes was professional practitioner academics, who rarely came to academia with the required $\mathrm{PhD}$, who could not easily turn their professional practice into REFable outputs, and for whom there were therefore minimal promotion prospects. The requirement for a $\mathrm{PhD}$ in recruitment meant that professional practitioners were being replaced by academic researchers, which reduced students' exposure to professional expertise. This group had raised concerns that 'fundamental' knowledge required for professional exemption should not be replaced in the curriculum 'to accommodate whimsical research areas'.

There was also concern that the promotion of research-informed teaching had shifted the focus away from the administration of teaching, for example checking timetables, updating handbooks, admissions and scrutiny of assessments, since these roles were poorly recognised and rewarded. However, an academic in architecture saw this as a positive change:

They've been self-indulgent in teaching and created an overly bureaucratic and burdensome world they can't extricate themselves from ... ridiculously complicated assessment procedures ...they've built a tower around themselves to give a sense of validity.

A potential threat to the new undergraduate law curriculum was the professional body that was considering introducing centralised assessments, which would force the curriculum back to preparing students to pass these assessments, and limit scope for innovations in teaching.

The decision to integrate research and teaching was also followed in more traditional disciplines in response to different contextual considerations. A history academic described how the disciplinary workgroup had been allowed to expand at about the same time the institutional mission changed and had been able to recruit young research-active academics with offers of guaranteed sabbaticals, who aspired to offering high-quality research-led learning experiences to students, who may have struggled to gain access to more prestigious universities. 
This created an environment where a history academic was able to pursue his own version of research-led teaching, engaging his students as partners in the research process by developing open-ended undergraduate modules around his next research project. In this way, teaching was used 'to drive and generate the research journey'. He argued that through this, students learnt to ask the right questions, how answers might emerge and how to search the literature. He differentiated his approach from that of colleagues, who he argued were fearful of saying to students 'I don't know', preferring to teach from their existing expertise. However, the culture within the disciplinary workgroup of collegial respect for academic autonomy meant that such differences in approach to teaching were respected. Students who found the unstructured and provisional nature of learning and the expectations to respond to critical questioning in seminars too challenging could choose modules with a more stable and known learning environment with clearly defined outcomes.

The change in institutional mission had enabled the disciplinary workgroup to forge an identity typical of humanities disciplines in research-intensive universities. They advocated a programme with extensive module choice built around their individual research interests. However, the discipline group also advocated a culture of collegial support in relation to teaching. This academic was helping research-oriented colleagues to develop undergraduate modules around their research interests in a way that could appeal to students, by developing broad-based modules around a specialist interest. He showed colleagues how this could draw undergraduate students into postgraduate study around their research specialisms.

The change in institutional mission had enabled a localised culture balancing academic freedom and collegiality to flourish, and the discipline was generally praised by the University for meeting research targets and teaching targets measured in the National Student Survey (NSS). However, the discipline was also required to meet institutional targets for student employability, which influenced the way research-informed teaching was developed. An institutional teaching innovation fund had been used to initiate placements in communitybased research projects, as well as an undergraduate research conference organised by students. It was argued these linked research-informed teaching to the development of transferrable skills required to meet the University's employability target.

\section{Splitting research from teaching}

In other disciplines, it was judged that the best way to meet institutional targets for teaching and research was to insulate teaching from research requirements and appoint additional research-active academics who were independent of teaching programmes. One of these new appointments, with a keen interest in research-informed teaching, said he had been unable to have much impact because of the structure of the academic programme in business, which separated teaching from research:

The teaching is organized through this system, so trying to break in there is like trying to break into Fort Knox, because it's all mapped out, who's doing what for the whole year.

He believed the decision to keep teaching and research separate was economic. The programme was structured around mass modules of up to 900 students with 4-5 academics teaching from pre-prepared PowerPoints, in order to achieve economic efficiencies and to satisfy franchised overseas providers that contractually required a common delivery method. For academics, it meant that most of their teaching was service teaching with few opportunities 
to teach in their subject areas. Mass modules were taught as a core curriculum across subject specialisms and were controlled by programme managers who were ultimately accountable to the faculty executive, who, he argued, prioritised administrative and economic efficiencies over both teaching and research:

Everything I've described, the size of modules, everything is in a box. It seems efficient but it isn't. Administratively it's efficient. Administration should be there to serve the core business, but I would argue in many respects the core business is there to serve the administration... they don't consider it as research and teaching at all, they just see bodies in classrooms.

The economic efficiencies of this model satisfied institutional income generation targets, creating a surplus that enabled the appointment of research-active staff whose only requirement was to produce outputs for the REF. It also freed up time through the workload model for teaching academics to produce REFable research, since they did not have to spend time preparing their teaching. While many academics wanted to integrate their research and teaching, structurally this met resistance:

I must say a lot of the academics here, their hearts are ethically in the right place, it's just the systematization and logistics, how we can free that up to get a happy medium with the economic efficiencies as well as the educational quality, and getting the research into that, and I don't know how successful we'll be.

This academic had sought to understand the systemic environment for teaching in the discipline and had worked out the possibilities and limits of his agency for influencing research-informed teaching, as well as the benefits for pursuing his research offered by the current model. It was this process of sensemaking that influenced his actions in pursuing (or not) research-informed teaching. The individual agency of this academic to engage with research-informed teaching was highly circumscribed by the context he encountered in his disciplinary workgroup. The split between research and teaching in this discipline made it very difficult to implement research-informed teaching, either research-led teaching or more active forms of enquiry-based learning.

However, other discipline groups that opted to split research, teaching and professional practice managed this in different ways in response to different contextual pressures, creating different possibilities for research-informed teaching.

The shift in institutional mission created an expectation that nurse educators would gain a $\mathrm{PhD}$ and publish; however, the priority for the disciplinary workgroup was to win the highly competitive NHS teaching contracts that were a key income generator for the University. As a result, teaching was prioritised over research, and in practice, she found little time in the workload to carry out research:

There is such constant monitoring that I don't think the University gets in any way. It doesn't enter their minds, for example, that last year we had to completely review the interview and recruitment process, had to fill in monthly spreadsheets ... we couldn't run the courses if we didn't do those things, they ask about these issues at validation ... so people are frustrated with the University because the 40:40:20 workload model is considered a joke.

As a nurse educator, research was valued through the lens of professional practice: 'to have any legitimacy in practice you have to be up-to-date with cutting edge research'. However, 
research engagement was driven by the professional body that scrutinised the curriculum to see where research was informing teaching in a specified list of topics:

That is where the driver to have quality teaching is so strong. They don't mind if you are active researchers, but you have to show in some detail where it (up-todate research on specified topics) is on the curriculum and where it is in practice competencies.

This tended to drive research-led (as opposed to enquiry-based) teaching in the undergraduate curriculum, where learning is informed by the latest research, but students are not actively involved in doing research.

\section{Mediating academic narratives of research-informed teaching in the shifting power relations between research, teaching and practice}

Another key issue that surfaced through the interview analysis was how changing power relations between research, teaching and practice were changing the way academics framed narratives of research-informed teaching. The expectation that practice-focused academics develop new identities and practices as researchers was generating innovative narratives of research-informed teaching integrating research, teaching and professional practice.

The expectation that academics become research-active led to intense discussions in practice-based design workgroups about what constituted research in these disciplines, which influenced how academics defined research-informed teaching. Where previously there were synergies between teaching and practice, with a focus on 'live projects' for students built around industry links, 'live projects' were now being rebadged as enquiry-based learning, linked to the focus on research.

Academics were keen to demonstrate how their design practice was a research process:

The research is the visuals ... animation is creative, a conceptual thing, but it's also very technical, you have to learn all the technical skills as well, you have to do your own research to do these things, each problem they have is different, they have to find out for themselves, so they become independent learners quite quickly to be able to do these projects in the animation field ... the research is part of it, but it's the thing they are striving to create and make, that's what's driving it.

It was argued students had to master a unique disciplinary terminology, such as how to design and critique a pipeline, developing and critiquing visual ideas through a storyboard, and researching images.

However, the above quotation reveals the ambivalence felt by both academics and students about seeing themselves as researchers, rather than practitioners. This was highlighted by another design-based academic, who argued his students did not see their design practice in research terms: 'You see this commonly in design that the students see research as something quite different to the activity of designing'. They tended to see research as something that will support the design activity rather than applying research skills to the design process.

The anxiety that the new focus on research was creating a schism between student expectations and the curriculum was experienced most keenly where professional staff were replaced with research-active staff. As an academic in media said: 
We pitch our courses to them on the basis that they are getting the benefit of people with industry-based experience, and that's what they want, they want a head start in their careers ... If they don't feel they are acquiring industry-related skills they won't feel they are getting their money's worth.

Some professional practitioner academics resisted efforts to re-narrate the curriculum as research-informed. An academic in architecture spoke of a colleague:

He said we are here to train professionals, that we were looking in the wrong direction. As far as he's concerned we've taken our eye off the game, and will end up creating people who are useless.

However, new narratives of the benefits of research for the architecture curriculum were also being forged. It was argued that approaching professional practice as a research process brought greater rigour to the way students approached professional enquiry:

They do research from the very beginning, but the paradigm is enquiry-based. They look at the history of a site and develop narratives out of that, and then take it into projects. Before it used to be implicit, but now we describe it as research ... every project you do in architecture is a unique research project ... the building becomes the research.

These narratives for the integration of research with teaching and professional practice drew on Boyer's model, focusing on integration through enquiry and scholarship. However, this narrative of integration was being developed against the grain of faculty narratives of research, which was felt to privilege theoretical research over practice-based research:

Most architecture schools struggle to articulate what they do in terms of research. It doesn't mean it isn't happening, it doesn't happen in a linear way. In Boyer's model we demonstrate our research in application and integration, rather than in discovery. Research has been hijacked by academics as books and articles.

Nevertheless, he had found it possible to reconstruct his identity as a research-active academic with something new to offer students:

I'm a different academic since I saw the value of being research-active ... I feel I operate at a different level now, it opens more windows. I feel I've got a really good 'feel for the game' now, so I can give this to students.

Academics also expressed ambivalence about the way the twin demands for income generation and research were reshaping the way students were involved in 'live projects'. Whereas previously 'live projects' in design were developed with the primary aim of enabling student learning, this was now seen as secondary to academics' ability to use 'live projects' to develop REFable research, and students were being actively engaged to provide case study data for the research:

I think the feeling is that if you don't make it REFable you are in trouble, the project lacks credibility and is undermined if academics are not REFed. Our work should always deliver value to governments and organisations, academically there should be new knowledge, and contribution to society.

In the context of these shifting power relations between research, income generation and teaching, he sought to redefine the benefits for students, who he argued developed a better 
understanding of research in the profession by being involved in real research projects, as opposed to one-off projects tailored to their learning needs.

However, this design academic was struggling to balance his commitments to teaching and research with the demands for income generation from industry, which he understood as the key driver:

I'd like to set it up as a research project, but I've been tasked with bringing in $£ 250,000$ for the project and running with it, so the research is secondary. Everyone talks about isn't it great I've got a $£ 250,000$ project, but no one talks about we really have to generate three journal articles for the REF.

Teaching was also increasingly being articulated in financial terms, rather than through the lens of the student learning experience:

The programme next door recruits 35 students. We only have 15 , so they say we are generating $\mathrm{x}$ amount of student income so we need this space, this resource.

An increasingly performative culture was experienced by academics across all disciplinary workgroups, which, in relation to research-informed teaching, was driving out space for teaching innovations in favour of measurable teaching outputs such as performance in the NSS. Academics, who had been active in leading innovations in research-informed teaching previously, said they were no longer able to find time to do so. An academic in design said:

The opportunity for looking at how to design research into teaching has disappeared... there is not enough time, the day-to-day job of programme director means you are constantly day-to-day working, so finding time for outside initiatives is really hard... I just haven't had the time to think ... and if you do your own research as well there are just no hours left.

This was echoed by an academic in media:

What drew me to this role was championing excellence in learning and teaching, but I haven't had a lot of time in the job to do that ... We are being asked to do remedial work rather than enhancing learning and teaching, so if the name was changed to NSS Lead it wouldn't be far off the mark - trying to fix the things that aren't working, from the tail, not the front ...

Another academic who had previously led innovations in enquiry-based teaching spoke of intense pressure to perform in the REF which led him to withdraw from undergraduate teaching to focus on research:

The joy is doing things with students ... the research I enjoy that, for all the sourness at the moment. If I didn't have that iron fist hanging over me all the time this would be the perfect job for me. I have a mix of teaching which I love, and research projects which are exciting for us, it's just the fear of failure that the system has created which doesn't allow us to breathe ... I wake in the night sweaty, panicky, not because of me, but things extraneous to me - it's not conducive to good work ... There is no space for what should be reflective because we are bombarded with more stuff ... there's no joy any more, because I feel I've got a ferule around my neck ... you end up scared of failure.

Given this experience of pressure to meet a range of performative targets, it is unsurprising that some academics withdrew from investing time in teaching innovations such as developing 
research-informed teaching, unless they could make it count, either where disciplinary workgroups submitted discipline-based educational research to the REF, as in law, or where individuals found ways of involving students in their research, as in history.

\section{Discussion}

\section{The value of analysing research-informed teaching as a social practice}

While current research on the implementation of research-informed teaching has focused on changing academics' beliefs about learning and teaching (for example, Brew and Mantai 2017), this research has explored how academics implement research-informed teaching using a social practice lens, which understands change as a process of learning through participation in social practices. When social practice theory is applied in academic contexts, it understands disciplinary workgroups as the environments though which academics learn about and change their practices of research-informed teaching. This approach brings into focus the social practices of disciplinary workgroups, and the unique contextual opportunities and constraints they create for constructing different approaches to research-informed teaching.

This social practice approach challenges individualist approaches to implementing research-informed teaching that understand the problem as a knowledge deficit of academics that needs to be remedied. Instead, it focuses attention on the possibilities and limits of academic agency created by the social practices of disciplinary workgroups.

This social practice analysis also challenges understandings of differences in approach to research-informed teaching as shaped by disciplinary epistemologies. Instead, it highlighted the socially situated practices of disciplinary workgroups shaped by unique structural opportunities and constraints that varied over time. These included practical contingencies linked to teaching in the discipline, such as fashions of thinking about research-informed teaching by professional bodies, or the demands of specific overseas franchised providers, but also included historical practices of teaching characteristic of disciplines in different types of institutions. Many of the differences in approaches to research-informed teaching were due to unique relationships between research, teaching and professional practice that had developed historically in disciplinary workgroups.

While disciplinary workgroups were diverse, they were also profoundly influenced by wider contextual forces. The change in institutional mission from teaching and professional practice to incorporate a new focus on research within a performative culture had a profound impact on the way academics understood and practiced research-informed teaching. However, the change in mission was experienced differently in different disciplinary workgroups, with different outcomes for approaches to research-informed teaching. Generally, disciplinary workgroups where research was integrated with existing strengths in teaching and professional practice created better opportunities for academics to develop rich new narratives for integrating research into teaching. However, the integration of research, teaching and professional practice required a faculty commitment to giving teaching and practice-focused academics time and space to develop new identities as research-active academics, and develop new narratives about how research informed the curriculum.

Any interventions to engage academics with research-informed teaching need to pay attention to the way research, teaching and professional practice are integrated, not just at an institutional level, but within disciplinary workgroups, and how this both creates and limits 
possibilities for academics to reinvent their identities and practices, both as research-active academics, and as teachers of research.

\section{Academic narratives as a space for agency}

While social practice theory does bring to the fore questions of social identity, there is a tendency to see these as the outcome of social practices, at the expense of more complex understandings of identity and agency. This paper has explored the value of approaches to identity developed in postcolonial literary theory, by focusing on the creative work of constructing coherent new narratives of agency in the face of powerful and often conflicting discourses. This approach has been used to highlight academic narratives of research-informed teaching that have been created in response to the often contradictory discourses of research, teaching and professional practice.

Postcolonial literary theory draws attention to narratives as 'work done at the seams' (Attwell 2005) of conflicting discourses that threaten to tear apart. It views these narratives of postcolonial subjects as provisional and unstable resolutions of often irreconcilable discourses. This is reminiscent of the 'fault lines' Krause (2014: 5) identifies in disciplinary cultures around different responses to the employability agenda, recognising the increasingly fractured nature of academic identities. In this research, the 'fault lines' surfaced between often conflicting demands of research, teaching and professional practice, while performative demands for income generation from all three activities were experienced as threatening the creative engagement of academics with their teaching and research.

The way disciplinary workgroups mediated the relationship between research, teaching and practice was critical in creating spaces (or not) for academics to reconstruct coherent narratives of research-informed teaching in a changed environment. Postcolonial literary theory reminds us of the personal pain involved in negotiating change, the loss of identity and the provisional nature of new identities carved out of unstable discursive environments. Experiences of pain and stress were evident in many of the interviews, particularly where disciplinary workgroups had given little consideration to integrating research, teaching and practice. However, where workgroups integrated these, academics were better able to reshape their practices of researchinformed teaching alongside their changing identities and practices as research-active academics.

The institutional focus on performative outcomes as a way of driving change meant that the academic work of creating coherent new narratives of research-informed teaching remained largely invisible. This research draws attention to the importance of academic agency as a creative force that dynamically constructs the relationship between research, teaching and practice. As Hattie and Marsh (1996: 533) argue, the integration of research and teaching cannot be assumed, but has to be actively constructed, often against the grain. Valuing academic narratives as sites both of tension and of creative agency can make us value the importance of this 'work done at the seams' of research, teaching and practice. It foregrounds the time and support academics need to make sense of changes in institutional mission as they recreate their own identities and practices through localised disciplinary narratives. Institutional efforts to implement research-informed teaching would do well to pay attention to the ways in which this academic work is recognised, workloaded and rewarded.

Open Access This article is distributed under the terms of the Creative Commons Attribution 4.0 International License (http://creativecommons.org/licenses/by/4.0/), which permits unrestricted use, distribution, and 
reproduction in any medium, provided you give appropriate credit to the original author(s) and the source, provide a link to the Creative Commons license, and indicate if changes were made.

Publisher's note Springer Nature remains neutral with regard to jurisdictional claims in published maps and institutional affiliations.

\section{References}

Archer, M. (2000). Being human: the problem of agency. Cambridge: Cambridge University Press.

Attwell, D. (2005). Rewriting Modernity: Studies in Black South African Literary History. Pietermaritzburg: Interpak.

Barnett, R. (2000). Realizing the university in an age of supercomplexity. Buckingham: SRHE and Open University Press.

Becher, T., \& Trowler, P. (2001). Academic tribes and territories: Intellectual enquiry and the cultures of disciplines. Buckingham: Open University Press/SRHE.

Bhabha, H. (1992). Freedom's basis in the indeterminate. October, 61, 46-57.

Blackler, F. (1995). Knowledge, knowledge work and Organisations: An overview and interpretation. Organization Studies, 16(6), 1021-1046.

Boud, D., \& Brew, A. (2013). Reconceptualising academic work as professional practice: Implications for academic development. International Journal for Academic Development, 18(3).

Boyer Commission. (1998). Reinventing undergraduate education: a blueprint for America's research universities. State University of New York, Stony Brook: Carnegie Foundation for the Advancement of University Teaching.

Brew, A. (2003). Teaching and research: New relationships and their implications for inquiry-based teaching and learning in higher education. Higher Education Research and Development, 22(1), 3-18.

Brew, A., \& Mantai, L. (2017). Academics' perceptions of the challenges and barriers to implementing researchbased experiences for undergraduates. Teaching in Higher Education, 22(5), 551-568.

Clegg, S. (2008). Academic identities under threat? British Educational Research Journal, 34(3), 329-345.

Durning, B., \& Jenkins, A. (2005). Teaching-research relations in departments: The perspectives of built environment academics. Studies in Higher Education., 30(4), 407-426.

Engestrom, Y. (2001). Expansive learning at work: Toward an activity theoretical reconceptualization. Journal of Education and Work, 14(1), 133-156.

Englund, C., Olufsson, A., \& Price, L. (2018). The influence of sociocultural and structural contexts in academic change and development in higher education. Higher Education. https://doi.org/10.1007/s10734-018-0254-1.

Fanghanel, J., \& Trowler, P. (2008). Exploring academic identities and practices in a competitive enhancement context: a UK based case study. European Journal of Education, 43(3), 301-313.

Gibbons, M., Limoges, C., Nowotny, H., Schwartzman, S., Scott, P., \& Trow, M. (1994). The new production of knowledge: the dynamics of science and research in contemporary societies. London: Sage.

Hattie, J., \& Marsh, H. W. (1996). The relationship between research and teaching: A meta-analysis. Review of Educational Research, 66(4), 507-542.

Healey, M., Bovill, C., \& Jenkins, A. (2015). Students as partners in learning. In J. Lea (Ed.), Enhancing learning and teaching in higher education: engaging with the dimensions of practice (pp. 141-162). Maidenhead: Open University Press.

Henkel, M. (2000). Academic identities and policy change in higher education. London: Jessica Kingsley.

Henkel, M. (2016). Multiversities and academic identities: Change, continuities, and complexities. In Organizing academic work: Teaching, learning, and identities. London: Routledge.

Jenkins, A., \& Healey, M. (2005). Institutional strategies for linking teaching and research. York: Higher Education Academy.

Krause, K. (2014). Challenging perspectives on learning and teaching in the disciplines: The academic voice. Studies in Higher Education, 39(1), 2-19.

Lave, J. (1993). The practice of learning. In S. Chaiklin \& J. Lave (Eds.), Understanding practice: perspectives on activity and context. Cambridge: Cambridge University Press.

Lyotard, J. F. (1984). The postmodern condition: a report on knowledge. Manchester: Manchester University Press.

Mathieson, S. (2012). Disciplinary cultures of teaching and learning as socially situated practice: Rethinking the space between social constructivism and epistemological essentialism from the south African experience. Higher Education, 63, 549-564. 
McNaughton, S., \& Billot, J. (2016). Negotiating academic teacher identity shifts during higher education contextual change. Teaching in Higher Education, 21(6), 644-658.

Neumann, R. (2001). Disciplinary differences in university teaching. Studies in Higher Education, 26(2), 135146.

Reich, A., \& Hager, P. (2014). Problematising practice, learning and change: Practice-theory perspectives on professional learning. Journal of Workplace Learning, 6(6-7), 418-431.

Roxa, T., \& Martensson, K. (2009). Significant conversations and significant networks: Exploring the backstage of the teaching arena. Studies in Higher Education, 34(5), 547-559.

Trowler, P. (2008). Cultures and change in higher education: theories and practice. Basingstoke: Palgrave Macmillan.

Trowler, P. (2014). Depicting and researching disciplines: Strong and moderate essentialist approaches. Studies in Higher Education, 39(10).

Wald, N., \& Harland, T. (2017). A framework for authenticity in designing a research-based curriculum. Teaching in Higher Education, 22(7), 751-765.

Wenger, E. (1998). Communities of practice: learning, meaning and identity. Cambridge: Cambridge University Press.

Wilson, A., Howitt, S., Wilson, K., \& Roberts, P. (2012). Academics' perceptions of the purpose of undergraduate research experiences in a research-intensive degree. Studies in Higher Education, 37(5), 513-526.

Yjiloki, O., \& Ursin, J. (2013). The construction of academic identity in the changes of Finnish higher education. Studies in Higher Education, 38(8), 1135-1149. 